\title{
STREETSCAPE TERRITORIES AND THE CASE OF ADDIS ABEBA
}

\author{
Kris Scheerlinck*
}

\begin{abstract}
Urban transformation is directly related to the planning, design and use of a series of urban infrastructures, from streets to highways, from pedestrian, bicycle, bus or train lines and their connecting transport hubs to rivers, canals or harbor facilities. They play an essential role in the transformation of the urban fabric. Recent societal changes, especially in developing countries, demanding higher mobility and urban interaction, influence the used planning and design strategies to transform or extend urbanized areas by planning or renewing these infrastructures. However, its relationship to the surrounding urban fabric, more specifically the collective spaces it constitutes at the level of the streetscape, is not always an initial or integral part of providing these infrastructures. In many cases, the urban fabric is wrapped around or fragmented by these infrastructural projects, causing scale contrasts and struggle to integrate within, generating processes of misappropriation or misuse. Especially in developing contexts, new infrastructures are often planned and built in a fast way, rarely considering the qualities of the existing urban fabric.
\end{abstract}

During the last decades, research on planning and design models related to the building or integrating of urban infrastructures has been developed and tested via specialised disciplinary approaches to produce insights on the relationship urban infrastructures have with the surrounding urban fabric (Secchi, 2013; Hasan, et. al. 2010; Shannon and Smets, 2009; De Maulder, 2008; Hillier, 1996;). However, additional in-depth research is needed to achieve critical insights on the relationship of infrastructures and their direct environments, starting from their constituent streetscapes considering the level of the street that defines the perception and use by the inhabitants at an intermediate scale.
This paper focuses on an ongoing research project in Addis Abeba (Ethiopia), where different visions and models of urban growth are at stake (Figure 1). The recent increase of (foreign) investment in major infrastructures, changes the city's streetscapes drastically. This large scale and formal approach of installing high speed trains, Light Rail Transit's (LRT) or expanded highways and ring roads, to stimulate urban growth, contrasts with the daily routines of the proper citizens that move around by walking or by means of mini buses, both adding to the informal qualities of the city's streetscapes. Within this multi-centred capital, the location of built and planned housing projects, commercial centres, administrative or commercial high rises is studied in relation to the present infrastructural axes and questions models of proximity, accessibility and permeability.

Keywords: Streetscapes, High Speed Trains, LRT, Addis Abeba, Infrastructure

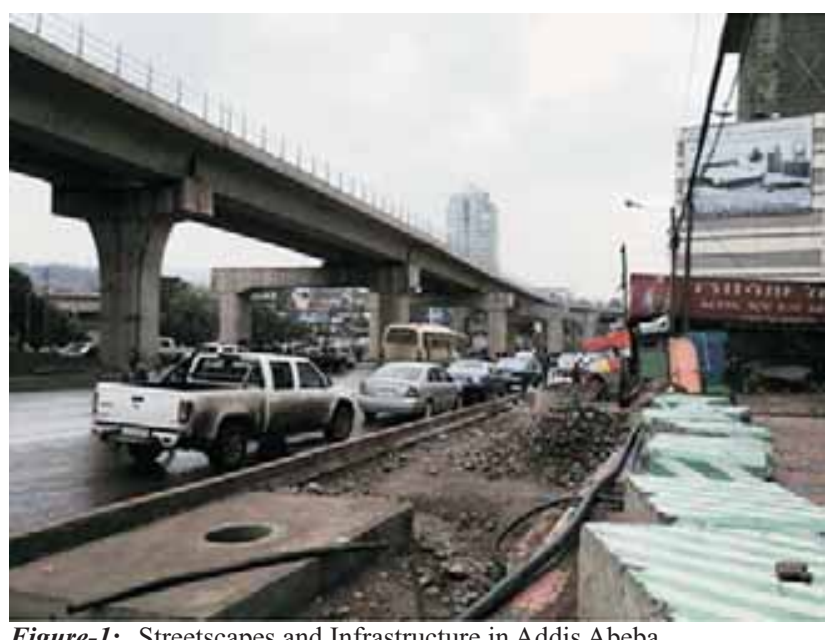

Figure-1: Streetscapes and Infrastructure in Addis Abeba.

- This paper was presented by Prof. Dr. Kris Scheerlink in the $10^{\text {th }}$ Seminar of Urban and Regional Planning, organized by the Department of Architecture and Planning, NED University of Engineering and Technology in 2015.

* Prof. Dr. Kris Scheerlinck, KU Leuven, Department of Architecture, Ghent/Brussels, Belgium, Email correspondence: kris.scheerlinck@kuleven.be 


\section{INFRASTRUCTURE AND URBAN FABRIC}

During the last decades, research on planning and design models related to the building or integrating of urban infrastructures have been developed and tested via specialised disciplinary fields. From traditional morphological research, analysing urban growth schemes in a historical framework (De Sola-Morales, 1997) to studying syntax integration values (Hillier, 1996). Both approaches allow to provide insights to the socio-morphological dynamics of space production. Mobility or transportation studies, mostly based on criteria of efficiency, capacity or performance (De Meulder, 2008) combine research methods focusing on how to densify the existing built environment (Ray et. al., 1999) or intensify its program, both linked to infrastructural interventions (Shannon and Smets, 2009). Other study fields focus on centrality or multi-centrality and the urban or periurban condition of areas in transformation seeking to guarantee maximum connectivity. Linked to these research approaches, new planning models have been studied to update zoning or land use planning (Khan, Moulaert, et. al., 2013), relying on strategic plans with a highly structural dimension laid out in time and a strong focus on participation. Environmental issues have gained importance due to the scientifically proven advance of global warming and its effects on urban growth or transformation (Khan, Quynh, et. al. 2013; Hasan, et. al., 2010). An increasing consciousness of the impact of urbanisation and need for sustainable wastemanagement (Hodson and Marvin, 2010) changes the agenda of planning or renewing infrastructures on a global scale. This environmental concern is undoubtedly related to discourses of how to read, interpret and plan the urban landscape, from conceptual to more pragmatic approaches to revalorize open landscapes. At alternating scales, the level of formalisation -that is the explicit or implicit delimitation of use of space- is studied (Lefebvre, 1996; Harvey, 2003) as available space is reducing and mobility requirements increase. Finally, the planning and design of urban infrastructure embodies models of social inclusion of exclusion (Smith, 1992; Sennett, 2013), due to the resulting change of accessibility and living standards for the inhabitants.

Despite the un-doubtable necessity of the above mentioned existing research approaches on the relation between infrastructures and the urban fabric, there is an increasing need to explore and unfold research approaches that start from an in situ condition, exploring mobility issues and the impact of infrastructure on the urban fabric in an immediate sense, operating at the level of the street. The case developed in this paper describes an ongoing research project, part of the Streetscape Territories Project, about Addis Abeba,
Ethiopia. The following heads describe the framework for the on-site analysis.

\section{STREETSCAPE TERRITORIES FRAMEWORK FOR ON-SITE ANALYSIS}

Streetscape Territories is the name given to an international research project (KU Leuven, Department of Architecture) that focuses on the transformation of the urban fabric and considers its streetscapes the protagonists. The research deals with the way architectural artifacts, open space, the property structure and its inherent accessibility and permeability configure streetscapes and how their inhabitants can give meaning to them.

This project focuses on models of proximity within a street, neighborhood or region and starts from the assumption that urban space, from the domestic scale till the scale of the city, can be understood as a discontinuous collective space (De Solà-Morales, 1992; Avermaete and Teerds, 2007; Scheerlinck, 2011, 2012, 2013), containing different levels of shared use that are defined by multiple physical, cultural or territorial boundaries (Habraken, 1998). How do people and buildings relate to each other and how does it contribute to the local identity of the built and social environment?

The intermediate scale (Bijlsma and Groenland, 2008), that is the scale between the architectural intervention and the urbanistic plan, defines the research domain. Within this research project, collective spaces that are characterized by an "between/among" space condition are read, mapped or designed: systems of streets, squares, gardens, parks, but also patios, porches, enclaves, covered or portico spaces, courtyards and all other interstitial areas are subject of research. The research consists out of systematic and comparative analysis of existing neighborhoods, streetscapes, public spaces, urban landscapes or complex buildings in different locations, based on research by design. It includes multiple approaches from different disciplinary fields and considers research and design simultaneous and integrated processes of developing urban projects. The overarching aim of the research approach is to provide new research methods and insights to facilitate a critical and productive discussion on the transformation of the contemporary urban fabric, manifested through its multiple streetscapes.

The Streetscape Territories research projects are based on the folowing principles, that together constitute the framework for analysis.

The project focuses on the territorial organisation of 
streetscapes explored in different contexts, studied as part of different cultures and defined by different social networks. It starts with the assumption that streetscape is subject of constant negotiation and part of scenario of uncertainty at different levels. Uncertainty is very important dimension in planning a design processs (Teerds, et. al., 2011) as we have no control on every single aspect of that process. Many elements remain unpredictable, unstable or even unkown in a political, environmental, social or economical way because of the multi-layered character of urban projects there is a certain complexity and non-linear process that often seems to overtake the overall urban development. For this reason, multiplicity, ambivalence and the undefinedness of a project are always the starting point of the Streetscape Territories projects. The research and design approaches are defined by five main concepts, described in the following part of the paper.

\section{Depth}

According to Habraken (1998), the built environment, defined by territorial organisation, is founded on the principle of inclusion within other territories. The author relates this very principle to the transition between private and public spaces. Imagining different accessibility patterns within this theoretical model of inclusion, that is, different ways of entering those territorial scenarios, Habraken defines in a clear way the concept of territorial depth. "Territorial depth is measured by the number of boundary crossings (...) needed to move from the outer space to the innermost territory" (Habraken, 1998:137). However, territorial depth is not a static parameter within a time framework, after the intervention of various urban agents, depth can increase or decrease, according to the specific characteristics and dynamics of the built environment (Figure 2).

Hillier and Hanson (1984) also refer to depth and describe how architecture structures the systems of space we inhabit and how those systems are related with a social life movement, encounter of social relations or avoidance are part of architectural social vocabulary. Apart from theoretical models that deal with space without a social context or studies of society without a spatial context, they propose a new model to understand the built environment, starting from applied disciplines. First, this means that a social context of spatial patterning is studied with a simultaneous analysis of a spatial context of social patterning. Second, they suggest a new method of analysis of spatial patterns: one that concentrates on the relation between local morphologic relations and global patterns. This includes a theory of pattern types and a description of a method of analysis. Above all, they believe in the non-hierarchical, abstract notions of spatial relations between buildings or other elements, defining the environment. They point out that syntactic generators of space are shape-free the study of space as a system is not about shape. Besides that, they dedicate a limited role to "distances" or "location" and focus on simultaneously existing relationships that are everchanging. In other words, they are interested in rethinking the concept of proximity at an urban scale.

According to the authors, buildings define empty volumes of space in between, which can be seen as ordering space. They mention that buildings seem to be physical artefacts, but that this illusionary transformation of space through objects means ordering relations between people. In other words, this constitutes a system of social relations. Hillier (1996) continues the analysis of space syntax and tries to define the concept of relations: “(...) relations, especially spatial relations are very puzzling entities. (...) We must accept that (...) the relation, like the term it relates, is not dependent on thoughts, but belongs to the independent world which thought apprehends, but does not create." This independent world is full of complex relational schemes, between areas, buildings, users, voids and program defined configurations. A configuration is "a set of relationships among things all of which interdepend in an overall structure of some kind (...) if we define spatial relations as existing when there is any type of link -say adjacency or permeabilitybetween two spaces, then configuration exists when relations between two spaces are changed according to how we relate one or both to at least one other space" (Hillier, 1996: 33)

\section{Collective Space}

Processes of spatial specialisation and socio-functional segregation go together with increasing thematisation and extreme systematisation of the built environment, understood as live configurations (Habraken, 1998). These configurations are defined by way the public realm is related to private spheres. Nevertheless, the traditional dichotomy of public versus private space looses strength as new models of space use and production arise. The recent mentioned spatial

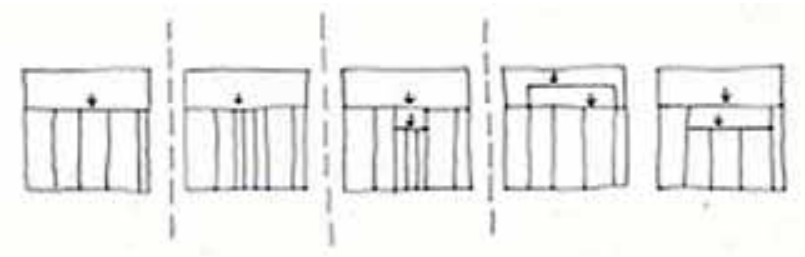

Figure-2: Increase in Territorial Depth, principle schematic diagrams. Source: (Diagram made after fig. 12.8: Habraken, 1998: 215) 
phenomena ask for a new understanding that is no more based on a division between private or public space but deals with collective use of space. In a way, Manuel de SolàMorales questioned two aspects of the traditional definition of public space that it should be publicly owned to have a collective dimension, and that it should be freely accessible by everyone. The author argues: "It is a fact that the city is the very place where the private domain can be, and often is, a social domain- just as much as or indeed even more than the public domain.(...) private buildings as public elements, radiating social meaning and value that extend beyond the actual buildings embody their urban character" (De Solà-Morales, 1992: 3-8). Avermaete et. al. (2007) while making a comparative study on "Architectural Positions on the Public Sphere", quote: "(...) to de Solà-Morales, both these attributes were becoming obsolete, and he argued that even in the most traditional European cities, much public life was developing elsewhere." The very nature of the property, that is who owns the piece of land or the building, becomes less important than the way we use space. They continue saying that, as a response, Manuel de Solà-Morales suggested extending the notion of public space to encompass new spaces such as "parking lots, shopping malls, vacation centres and cinema complexes." He called these collective spaces and argued that architects should seek broader responsibility for their design. They should not concede their design to commercial logic and developer standards, but rather seek to transform them into challenging new fields of architectural investigation. De Solà-Morales described this task as "the urbanisation of the collective territory." The author continues: "the civic, architectural, urban and morphological richness of a contemporary city resides in the collective spaces that are not strictly public or private, but both simultaneously. These are public spaces that are used for private activities, or private spaces that allow for collective use, and they include the whole spectrum in between. Moreover, in the past decades the design of these collective spaces seems to have become an important modus operandi to intervene in the contemporary city. At the intersection between an architectural and an urban scale, architects and urban planners design projects that, through their character and hybridisation of privacy and publicity, contribute to the civic, typological and morphological richness of the city" (De Solà-Morales, 1992: 3-8) (Figure 3).

The author suggests interconnecting private, enclosed spaces, to upgrade and turn them into parts of collective realm to include the particular into the sphere of the influence of the public. In order to do this, formal as well as informal processes of making collective spaces need to be monitored.

\section{Proximity}

The concept of depth and its correspondent models of proximity and accessibility are undoubtedly related to the use of space in a more exposed or intimate way, in a more collectively or individually used way. As mentioned before, depth was originally defined as the amount of boundary crossings needed to move from the outer space to the innermost territory. Outer space can often be related to public realm while the innermost territory often refers to private use of space. However, one might need to study these theoretical connotations: the configurational understanding of depth as a complex system of relations, requires a profound study on what is understood as public and private and what are the relations in between: this refers to models of proximity. Proximity depends on individual or collective spacing mechanisms that define a certain model of space production and space organisation. Territorial depth as an access configuration, can possess different recipes of proximity: each configuration is defined by a set of distances at different scales.

In "Territory without a model" Manuel de Solà-Morales describes a different meaning of places, unlike the traditional "genius loci" concept: "the expected sensation of voids and the indifference of its constructions" (De Solà Morales, 1997:21). He refers to the rising importance of periphery that is no more based on tactics of repetition and differences but on a system of relative distances. As the dialogue between the building and the urban surrounding system became an individual one, distances loose their absolute value, they seem to belong to a more complex urban matrix. The author argues that the distance between areas or autonomous packages defines the very law that constructs peripheries, the notion of distance obtained an abstract dimension. However, the importance of this concept gets even more obvious by looking at it at the scale of the urban project: the daily experiences are now defined by sets of

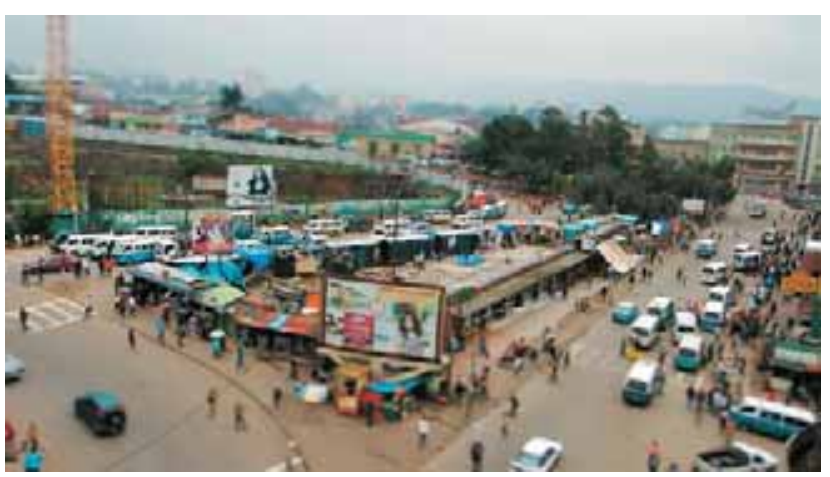

Figure-3: Collective Spaces in Addis Abeba. Source: Still from video by Mentens and Parachini, 2014 
minimal or maximum distances (Figure 4). Important became the distance between properties, between properties and natural resources, between properties and infrastructures, between properties and high employment areas. Instead of defining density, one ended up defining sets of rules of relative distances, that in suburban conditions might be different as in downtown areas. In a way, one defines and measures time and distance, comparing systematically with other configurations.

\section{Spatial Delimitation}

The next concept refers to spatial delimitation, an aspect that during the next decade will increasingly define the discours on urban projects. This is becoming more important not only responding to issues of safety and security but at the same time to the different ways of upgrading the social status, of differentiating yourself from your neighbour. The more one can afford to separate oneself from public life, the higher the social status becomes? Spatial mechanisms, and the increasing interest in spatial explicit boundary delimitations (fences, walls...) relate to a new territorial balance mentioned by Madanipour (2003) and Sennett (2013)

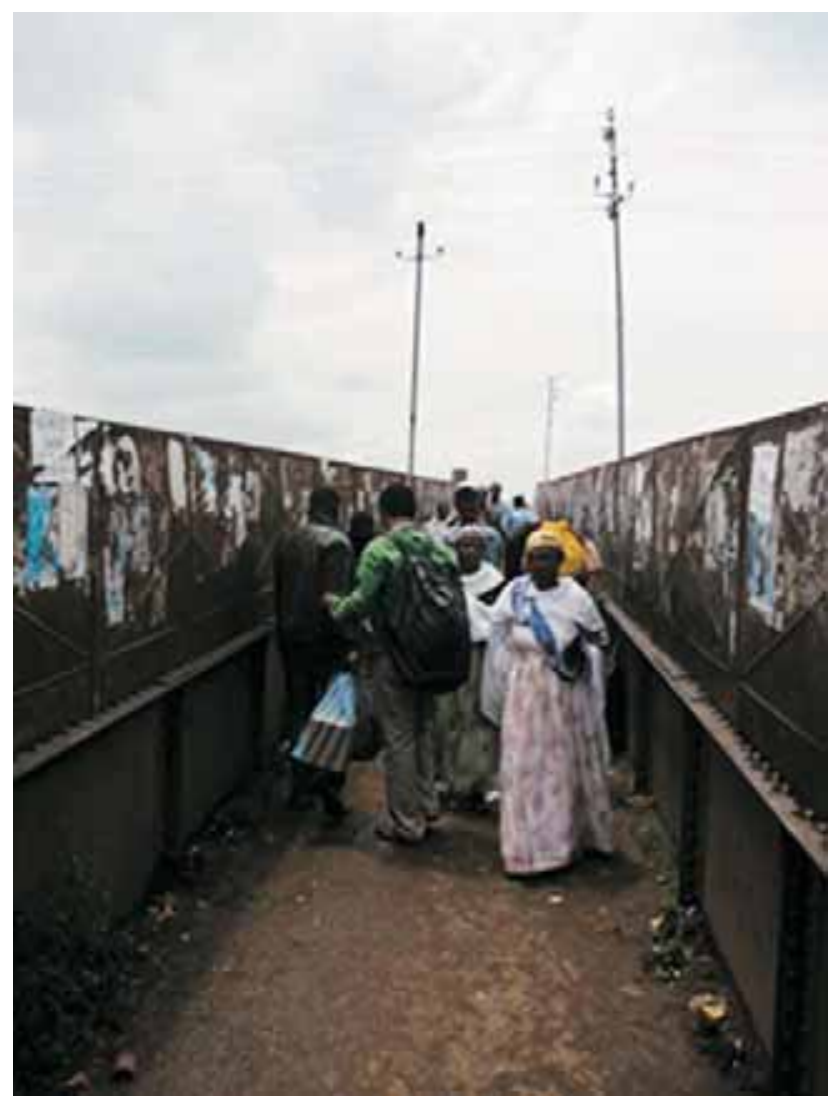

Figure-4: Proximity: pedestrian bridge near station area. Source: Pictures by De Cooman (2013) and student group some time ago. On a global scale, and specifically in developing contexts, one can easily detect the increasing use of extreme fencing tactics, of spacing mechanisms with disproportional physical distances. There seems to be a growing obsession about applying preplanned territorial transitions in urban projects, avoiding spontaneous overlap scenarios and restricting gaps or margins in the planning of depth configurations, as uncertainty in the interpretation of space is avoided (Figure 5).

\section{Openness and functional indetermination}

The last concept refers to openness, spatial tolerance, the needed discussion about the level of functional determination in urban projects. Lately, it seems as if projects or neighborhoods can no more be developed based on their spatial qualities and relations with the surrounding urban context but depend increasingly on programming spaces, as they often guarantee the financial backbone for development. Marot (2006) and Van Daele (2014) also mention this when reviewing contemporary urban or landscape projects. The overprogramming, exclusive focus on functional issues or even the description of ideal use or behaviour in urban space (Sorkin, 2007) leads to a simplification of urbanity and disable possible interpretations of a multiple nature, needed to construct a socially sustainable environment (Figure 6).

\section{THE CASE OF ADDIS ABEBA}

The previously described concepts were used to conduct a research project on the case of Addis Abeba, the capital of Ethiopia and of the African Union. This city experiences an exponential growth of population due to the internal growth

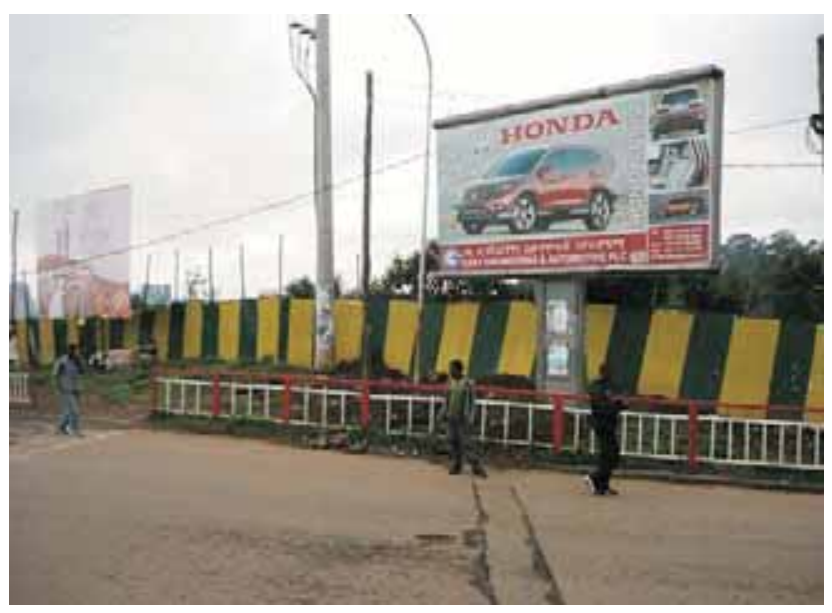

Figure-5: Spatial delimitation: all-round fencing in Addis Abeba. Source: Pictures by De Cooman (2013) and student group 


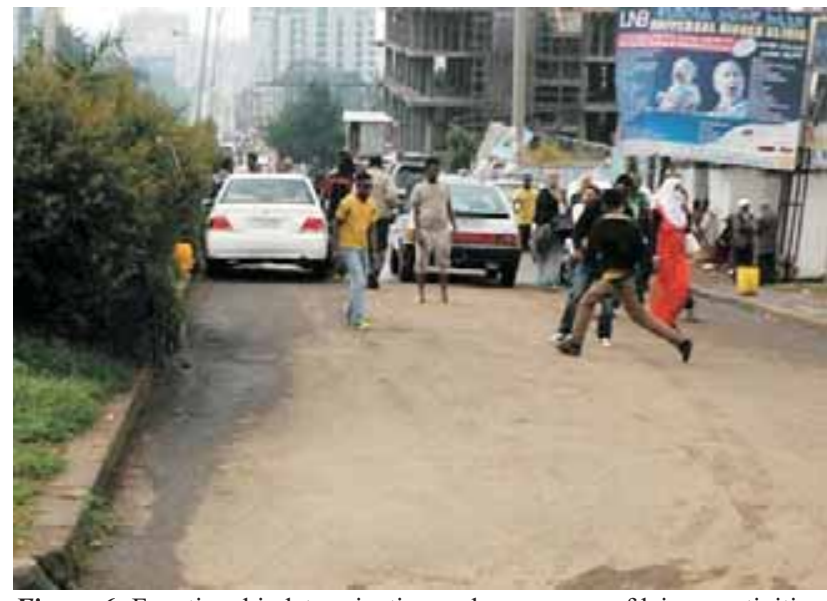

Figure-6: Functional indetermination and emergence of leisure activities in Addis Abeba's streetscapes.

Source: Pictures by Ken De Cooman and student group

but mostly as a result of a flight from the rural areas to the city, in most cases to the capital. Here, signs of urbanisation are omnipresent as the city is being dictated by various large scale infrastructures, responding to its almost uncontrollable growth. Global investments and mixed financial partnerships do not only invest in the city by means of real estate developments like shopping malls, residential gated communities and large scale offices and hotels, they also increase the pressure on connectivity and mobility within the city. These new large scale developments demand the construction of new highways, ringroads, LRT lines, train lines and stations, often imposed onto a fragile built environment, still characterised by strong informal processes of space production. Formal large scale infrastructures seem to contrast with more vernacular surroundings or housing typologies (the "kebeles" for example) and cut through them in a radical way. For the last ten years, the city government has been focusing on adding these infrastructures, designed in an often disproportionate way, defining a rather harsh relationship with the urban fabric. Studying and understanding the very balance (or conflict) between formal and informal transformation processes, related to the insertion of new infrastructure into the existing urban fabric, is the main goal of the ongoing Streetscape Territories research project. This research project consists a remote approach, combined with on-site analysis in different moments (two times six weeks research stays project by six Master students and six month remote analysis by the Streetscape Territories research team). Besides the initial thematical mapping of the existing and planned infrastructures, in situ reconnaissance was done, with collaboration of EiABC university and local planning office. The initial mapping and analysis (Figure 7) about the planned highways, ringroads, LRT and train lines, based on information provided by the official planning offices, illustrate

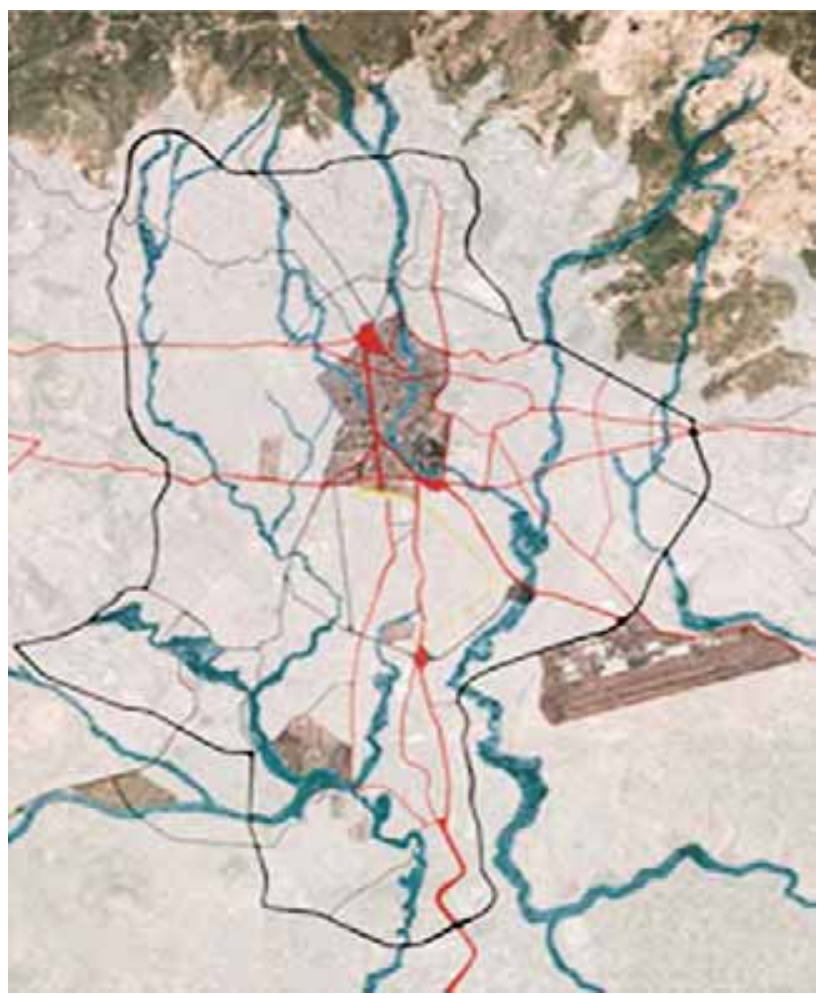

Figure-7: Initial Mapping of Centrality and Large Scale Infrastructures in Addis Abeba.

the used vision and strategy to "complete" a metropolitan system, adressing a notion of centrality. The city is being reconnected and developed with the area around Churchill Road as its centre of gravity, providing it fast connections to other infrastructures like the airport or commercial developments. This means the construction of major roundabouts, allowing the foreign investment in the construction of the LRT lines, remodelation of the central station area located at the southern part of Churchill Road etc. Nevertheless, the following on-site analysis, demonstrated a different reality.

"The way in which you perceive a city is closely related to how you move within it. And in the contemporary city, transportation has became the language able to establish hierarchies, rhythms and new possibilities in the urban space".

So, as $19^{\text {th }}$ century European intellectuals learned Italian in order to read Dante, and as English architecture critic Reyner Banham learned to drive in order to read Los Angeles, to read Addis Abeba we learned to use what today is the (more-or-less) fastest, cheapest and most popular form of public transport in Addis Abeba, the minibus. 
The minibuses connect different sub-centers all around the city, following the main streets (roughly the ones with asphalt). The resulting network is extending all over Addis Abeba, from the Entoto Mountain Range in the north to the extreme south, and from the west to the recent eastern expansion, with a web of lines structured around these different centers, without a single major gravity point.

The minibuses aren't therefore just the best way to experience the totality of the city, but actually their organization also reflects one of the most inherent characteristic of Addis Abeba: the absence of a main center (Mentens and Parachini, 2014) (Figure 8).

Indeed, the current structure of the metropolitan system is not characterised by a centre, but rather by a field of intermittent areas, changing in intensity during time (Figure 9). Not only is there no real centre, it is even hard to define the city as multicentral, as the functioning of the city defined by clusters of intense activity like for example the Merkarto Market Area seems to change during the day or the week.
As a consequence, mobility systems are emergently adapted to that, as people move around by minibuses that adapt their routes and schedules according to the daily needs. Looking back at the historic urban growth of the city, one can actually trace this time-dependent multicentrality in the foundation of the city, as the multiple military camps of the main warlords, located on several hills in the area defined the growth of the city during the last two centuries. Nevertheless, this specific kind of multicentrality, strongly related to an informal space production, seems to be questioned, avoided or even neglected by the municipal or metropolitan government that tries to impose a more traditional hierarchy of one main centre on the city's layout, reinforced by new transport infrastuctures. The construction of the new LRT line, of new ringroads and highways or new train stations is indeed planned to re-orient the growth of the metropolis. The attention goes to developing large scale projects (shopping malls, hotel complexes, administrative centres etc) that allow the city to ignore its existing urban fabric, mostly defined by informal processes of space production. It also means the involvement of foreign

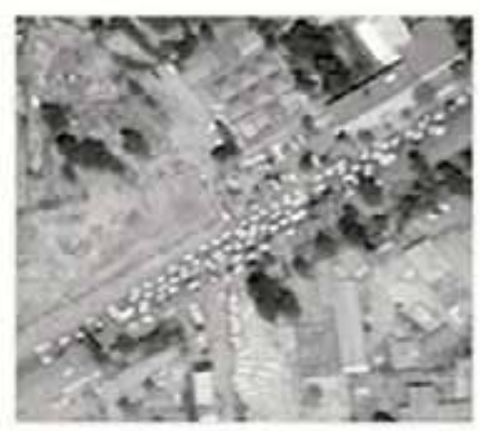

Mexico/Shebele

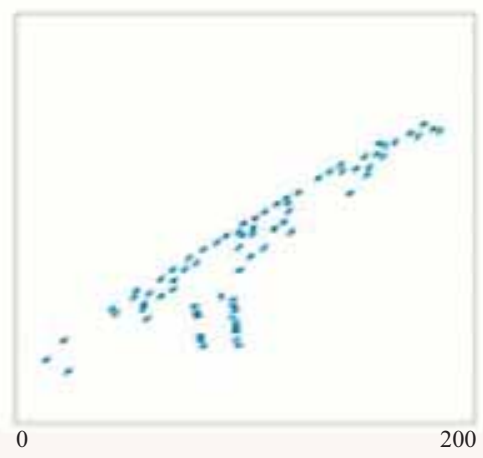

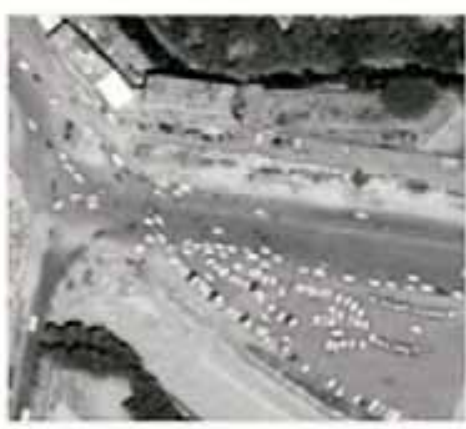

Meskel/Stadium

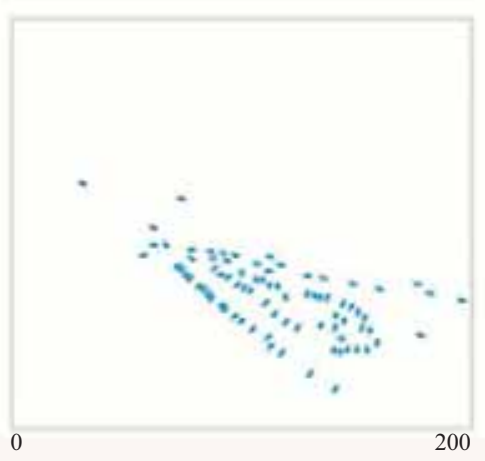

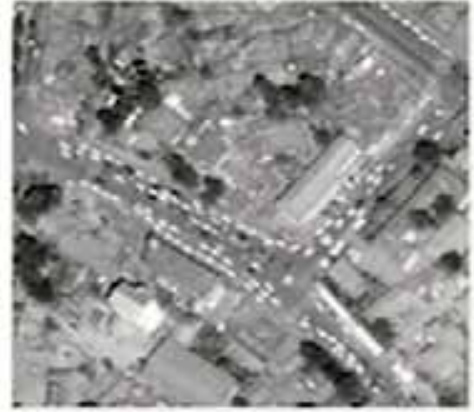

Kazanchis

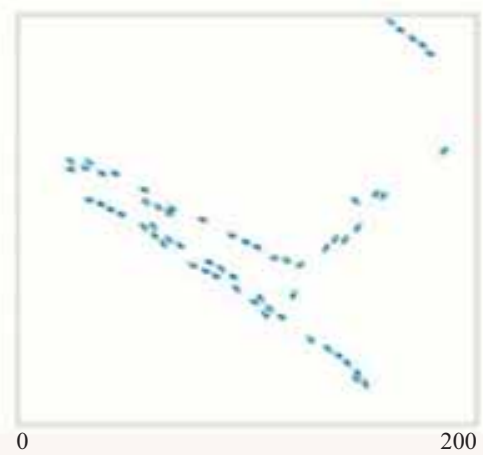

Figure-8: Photographic mapping of minibus itineraries in Addis Abeba and arial maping of the location of the minibuses in various centres in the city. Source: Lander Mentens and Matteo Parachini 


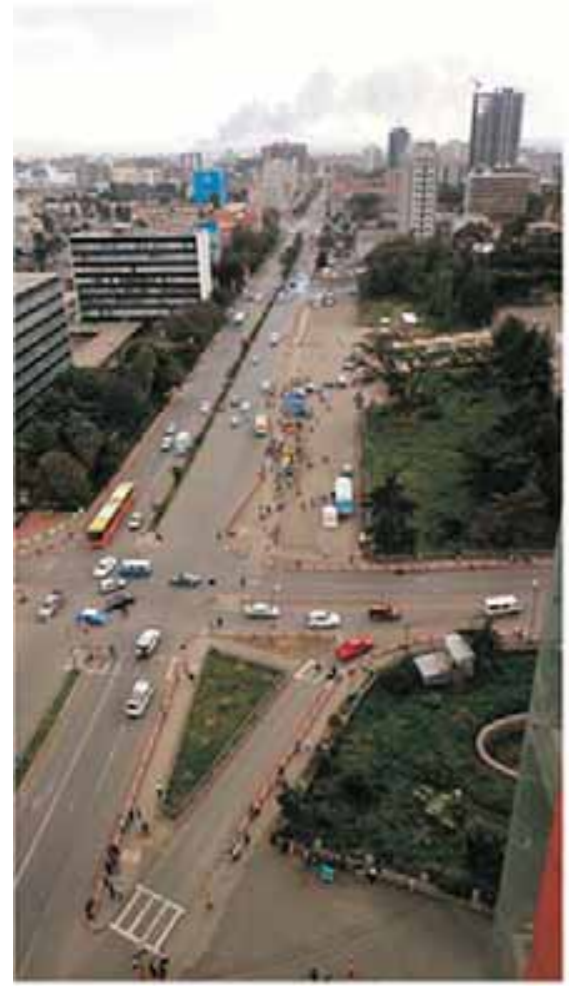

Current Situation

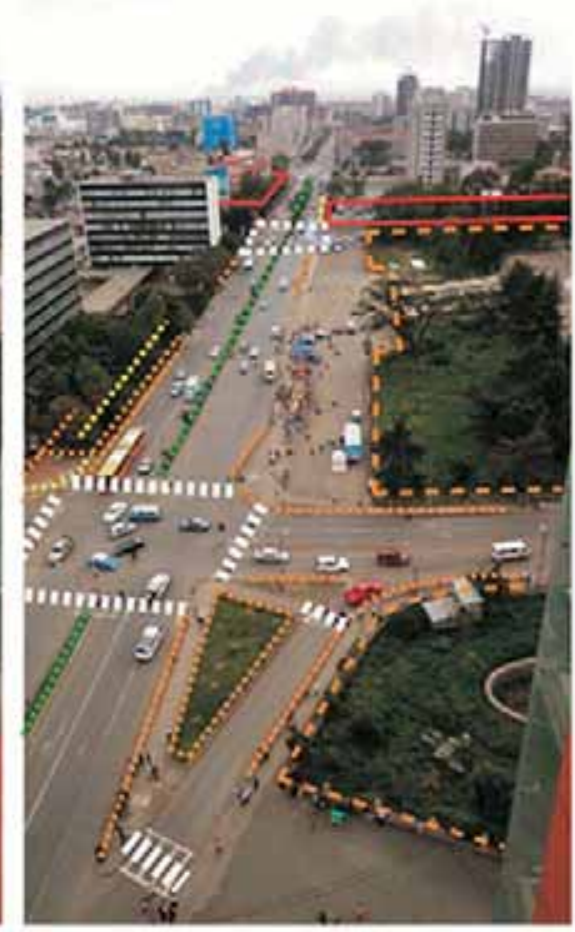

Highlightened Situation

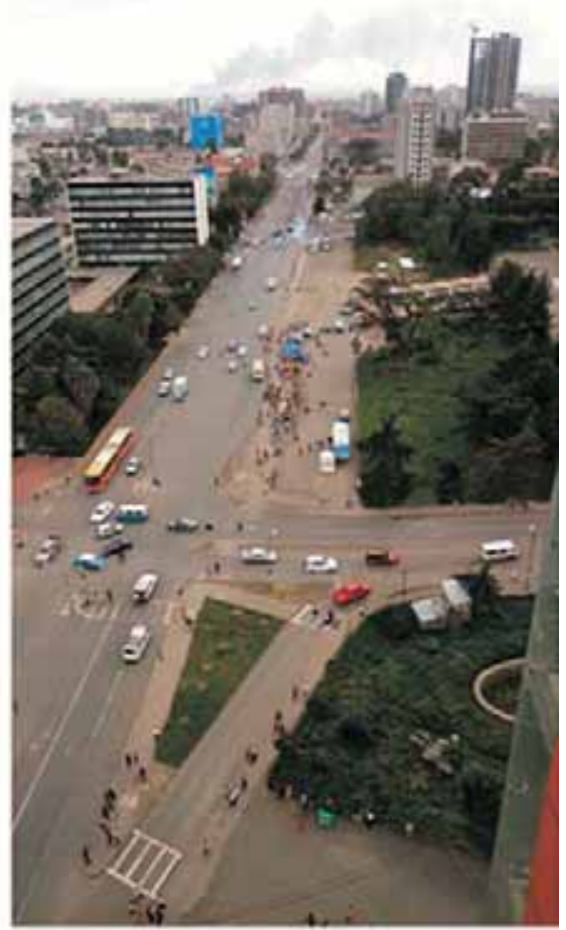

Hypothetical Situation

Figure-9: Analysis of explicit boundary delimitation and graphic simulation of absence of fences, walls etc. around Churchill Road.

(mostly Chinese) investors to finance the operations. The result of these interventions is a highly fragmented and specialised urban fabric, where high-tech LRT lines literally cut through areas defined by "kebeles", where large scale roundabouts contrast with a small scale residential areas defined by informal economies, where disproportioned avenues avoid any integration in the existing urban landscape. The large scale infrastructure investements seem to attract corporate driven (foreign) developments, while they ignore the relationship with the Grand Housing Programme that was set up to provide a home to the fastly growing population, as the LRT lines do not match the location of these large scale projects.

The on-site analysis of the relationship between infrastructure and the urban fabric, through systematic observation of different transport hubs in the city, and elaborating a thematic photographic, video and graphical mapping, however showed another characteristic of the Ethiopian capital: signs of resilience. Unlike the noncontextual or disproportionate design of the urban transport systems, these urban hubs seem to be redefined and optimised by informal processes. Their adjacent open spaces are massively appropriated by informal economies, that again trigger the adaptation of the more informal transport modes, like the mini buses. This phenomenon is common in developing contexts but in the case of Addis Abeba, the contrast between the glossy developments and the resilient informal system seems to be more articulated.

\section{CONCLUSION}

This ongoing research did provide some initial conclusions:

- The historic multicentrality in the city is reinforced by informal growth and related daily routines of the inhabitants

- Emergent informal transport systems confirm this multicentrality

- Proximity is not an organising principal: transport networks are laid out to trigger new developments, not embrace existing configuration of living, work and recreation areas within the city 
- New infrastructure projects, mostly as a product of foreign investment, do impose a strong centrality within the city, generating many local conflicts and highlighting contrasts between formal and informal space production

- These mentioned spatial contrasts generate again processes of emergent productivity

- One can detect a strong collective structure based on territorial organisation, use and program, not based on form

- The all-round explicit delimitation of space (fencing) is in strong contrast with emergent uses of space, especially for the new infrastrcuture projects that are planned in a top down way, causing a loss of complexity with territorial configurations
- One can detect an increasing explicit programming of space and an increasing planned segregation and specialisation that is not occuring spontaneously but intentionally programmed as such

Addis Abeba's streetscapes show an interesting relation between the newly planned infrastructures, responding to the rapid urban growth, and the surrounding urban fabric. It seems like formal and informal procceses of space production generate a chain of reinventing urban centralities and by this, show a high level of resilience at the level of the city as well as at the level of the transforming neighbourhoods. In this way the city is able to absorb the multiple needs for change. These forming dynamics however, need to be carefully monitored, and in most cases balanced in a more carefull manner, to maintain the richness of the urban fabric, guaranteeing a socially sustainable city for all.

\section{REFERENCES}

Avermaete, T., Teerds, H., 2007, 'Architectural positions on the public sphere: The 2007 Delft lecture series', Places, 19.2.

Bijlsma, L., Groenland, J., 2008, The intermediate size: A handbook for collective dwelling, SUN. Nijmegen.

De Meulder, B., 2008, 'Old dispersions and scenes for the production of public space', in Verbakel E., Segal R. (ed.) Architectural Design, Cities of Dispersal, Academy Press, Lagos.

De Solà-Morales, M., 1992, 'Public and collective space: The urbanisation of the private domain as a New challenge', in Oase, no. 33, reprinted in A matter of things, Nai Publishers, Rotterdam.

De Solà-Morales, M, 1997, 'Territoris sense model', Papers, Regió Metropolitana de Barcelona, no 26.

De Cooman, K., 2013, Masters design studio (studio group discussions), KU Leuven, Brussels.

Habraken, N.J., 1998, The structure of the ordinary, MIT Press, Cambridge.

Harvey, D., 2003, 'The right to the city', International Journal of Urban Regional Research, 27.4, 939-941.

Hasan, A., Sadiq, A. and Ahmed, S., 2010, 'Planning for high density in low-income settlements: Four case studies from Karachi', IIED Human Settlements Working Paper Series, Urbanization and Emmerging Population, Issues - 3. IIED, London.

Hillier, B., 1996, Space is the machine, University Press, Cambridge.

Hillier, B., Hanson, J., 1984, The social logic of space, University Press, Cambridge.

Hodson M., Marvin S., 2010, World cities and climate change: Producing urban ecological security, Open University Press, Milton Keynes..

Khan, A., Moulaert, F., Schreurs, J., 2013, 'Epistemology of space: Exploring relational perspectives in planning, urbanism, and architecture', International Planning Studies, 18 (4), 223-236.

Khan, A.Z., Quynh, L.X., Canters, F., Corijn, E., 2013, Understanding environmental conflicts for sustainable development. Sapienza University Press, Rome. 
Lefebvre, H., 1996, 'The Right to the city’ in Writings on cities, Blackwell, Oxford.

Madanipour, A., 2003, Public and private spaces of the city, Routledge, London.

Marot, S., Colafranceschi, D. (ed.), 2006, Suburbanismo y el Arte de la Memoria, Gustavo Gili, Madrid.

Mentens, L. and Parachini, M., 2014, Masters dissertaion, KU Leuven, Brussels.

Ray, M.A., Sherman, R., Zardini, M., 1999, Density dilated, Lotus Quaderni Documents, Milano Elemond S.P.A, Milan.

Scheerlinck, K., 2011, 'Privacy and depth configurations: Architektura and urbanizmus'. Journal for Architecture and Town Planning Theory, 2,166-185.

Scheerlinck, K, 2012, 'Depth configurations and privacy. proximity, permeability and territorial boundaries' in Urban Projects, in Carucci, M. (ed.). Revealing privacy: Debating the understandings of privacy, Am Maine Peter Lang, Frankfurt, 89-104.

Scheerlinck, K., 2013, Collective spaces streetscape territories notebook, Notebooks 2, KU Leuven, Brussels.

Secchi, B. and Vigano, P., 2013, 'De horizontale metropool', Oase, Vol 89: 94.

Sennett, R., 2013, The public realm. borders and boundaries, viewed 23 April 2015, from .

Shannon, K., Smets, M., 2009, The landscape of contemporary infrastructure, NAI Uitgevers, Rotterdam.

Smith, N., 1992, New City, 'New Frontier: The Lower East Side as Wild, Wild West', in Park. Sorkin, M. (eds.) Variations of a Theme, Hill and Wang, New York.

Sorkin, M., 2007, Indefensible space: The architecture of the National Insecurity State, Routledge. New York.

Teerds, H., Havik, K., Patteeuw, V., 2011, 'Productive uncertainty, indeterminacy in spatial design, planning and management', Oase \#85, NAI010 uitgevers. Rotterdam.

Van Daele, E., 2014, 'Hybrids as open signifyers.' PhD thesis, Faculty of Architecture, Universito of Brussels, Ghent/Brussels. 